Laser Chem., 1999, Vol. 19, pp. 397-401

Reprints available directly from the publisher Photocopying permitted by license only
(C) 1999 OPA (Overseas Publishers Association) N.V.

Published by license under

the Harwood Academic Publishers imprint, part of The Gordon and Breach Publishing Group.

Printed in India.

\title{
TRIPLET 1-NITRONAPHTHALENE AND COMPETITIVE ENERGY AND ELECTRON TRANSFER REACTIONS WITH TRANS-STILBENE
}

\author{
T. FOURNIER ${ }^{\mathrm{a}}$, G. D. SCHOLES ${ }^{\mathrm{b}}$, I. R. GOULD ${ }^{\mathrm{b}}$, \\ S. M. TAVENDER ${ }^{a}$, D. PHILLIPS ${ }^{\mathrm{b}, *}$ and A. W. PARKER ${ }^{\mathrm{a}}$ \\ ${ }^{a}$ Lasers for Science Facility, Central Laser Facility, CLRC Rutherford \\ Appleton Laboratory, Chilton, Didcot, Oxon, $O X 11$ OQX, UK, \\ ${ }^{\mathrm{b}}$ Department of Chemistry, Imperial College of Science Technology and \\ Medicine, London, SW7 $2 A Y, U K$
}

(Received 14 May 1997)

\begin{abstract}
A time resolved resonance Raman $\left(\mathrm{TR}^{3}\right)$ study of 1-nitronaphthalene (1NN) first triplet excited state in various solvents is combined with ab initio calculations to determine the nature and the geometry of this state in environments of different polarity. A transient absorption and $\mathrm{TR}^{3}$ study of the reactions of triplet $1 \mathrm{NN}$ with trans-stilbene $(t \mathrm{~S})$ in solution in both non-polar and polar solvents is reported. In polar solution, ${ }^{3} 1 \mathrm{NN}$ acts as an electron acceptor whereas in non-polar solution only energy transfer to $t \mathrm{~S}$ is observed. Moreover, at high concentrations of $t \mathrm{~S}$, the radical cation $t \mathrm{~S}^{+}$reacts with ground-state $t \mathrm{~S}$ to form a dimer radical cation $\left(t \mathrm{~S}_{2}\right)^{+}$. Differences between the Raman spectra of the monomeric and the dimeric radical cations are reported in the 1500 $1650 \mathrm{~cm}^{-1}$ region. The switch from energy to electron transfer when going from nonpolar to polar solutions is discussed in terms of the Marcus-Hush theory of electron transfer.
\end{abstract}

Keywords: Raman; energy transfer; electron transfer; triplet state

\section{TRIPLET 1-NITRONAPHTHALENE}

Most aromatic nitro-molecules are known to be non-fluorescent and their excited states and photochemistry have been the subject of many studies [1]. Triplet $1 \mathrm{NN}$ is known to be formed quickly $(<25 \mathrm{ps})[2]$

*Corresponding author. e-mail: d.phillips@ic.ac.uk 
and with a high yield $(0.63$ in EPA at $77 \mathrm{~K})[3]$. However the nature of this state is not clear from the literature; whilst some authors propose $\pi-\pi^{*}$ state [4], others an $n-\pi^{*}$ state [5], some even suggest that the lowest energy state switches from $n-\pi^{*}$ to $\pi-\pi^{*}$ with an increase of solvent polarity [1c].

The equilibrium ground state geometry of $1 \mathrm{NN}$ was determined using an ab initio RHF wavefunction with a $6-31 \mathrm{G}(\mathrm{d}, \mathrm{p})$ basis set and analytical gradients[6]. Harmonic frequencies were calculated analytically and were found to be in good agreement with the observed Raman frequencies. Equilibrium geometries and harmonic frequencies of the first two excited triplet states were determined using the configuration interaction singles (CIS) method. The calculated structures indicate that the main difference between ground and first triplet state is the change in angle between the $\mathrm{C}-\mathrm{NO}_{2}$ plane and the aromatic plane; $45^{\circ}$ and $37^{\circ}$ in the ground and first triplet state respectively. In each case, atomic charges on the $\mathrm{NO}_{2}$ moiety were calculated to be ca. $+0.5(\mathrm{~N})$ and -0.5 (both $\mathrm{O}$ ) from a Mulliken population analysis. On the other hand, the second triplet state is characterised by a strong change in electron density on the atoms of the nitro group, now roughly $0(\mathrm{~N})$ and -0.2 (both $\mathrm{O}$ ), accompanied by an important geometrical change in the $\mathrm{NO}_{2}$ arrangement; whilst one $\mathrm{C}-\mathrm{N}-\mathrm{O}$ plane is almost perpendicular to the aromatic plane (with the oxygen atom above it), the other $\mathrm{C}-\mathrm{N}-\mathrm{O}$ makes a $48^{\circ}$ angle with the aromatic plane (with the oxygen below it).

The calculations show that the lowest triplet state is of $\pi-\pi^{*}$ nature and the second triplet state, estimated to lie less than $0.1 \mathrm{eV}$ above the former in the gas phase, is of $n-\pi^{*}$ type. However, the $n-\pi^{*}\left(\mathrm{~T}_{2}\right)$ state has a lower dipole moment $(2.9 \mathrm{D})$ than the $\pi-\pi^{*}\left(\mathrm{~T}_{1}\right)$ state $(4.9 \mathrm{D})$. Hence $T_{2}$ would not be expected to be stabilised relative to $T_{1}$ in a polar solvent. This is consistent with the $\mathrm{TR}^{3}$ data, where there was little difference in the Raman spectra in non-polar and polar solvents (Fig. 1) and the observed frequencies for the lowest triplet state were well in agreement with the calculated ones.

\section{REACTIONS WITH TRANS-STILBENE}

By exciting $1 \mathrm{NN}$ and $t \mathrm{~S}$ solutions in carbon tetrachloride $\left(\mathrm{CCl}_{4}\right)$ and acetonitrile $(\mathrm{MeCN})$ with a $355 \mathrm{~nm}$ laser pulse (3rd harmonic of a 


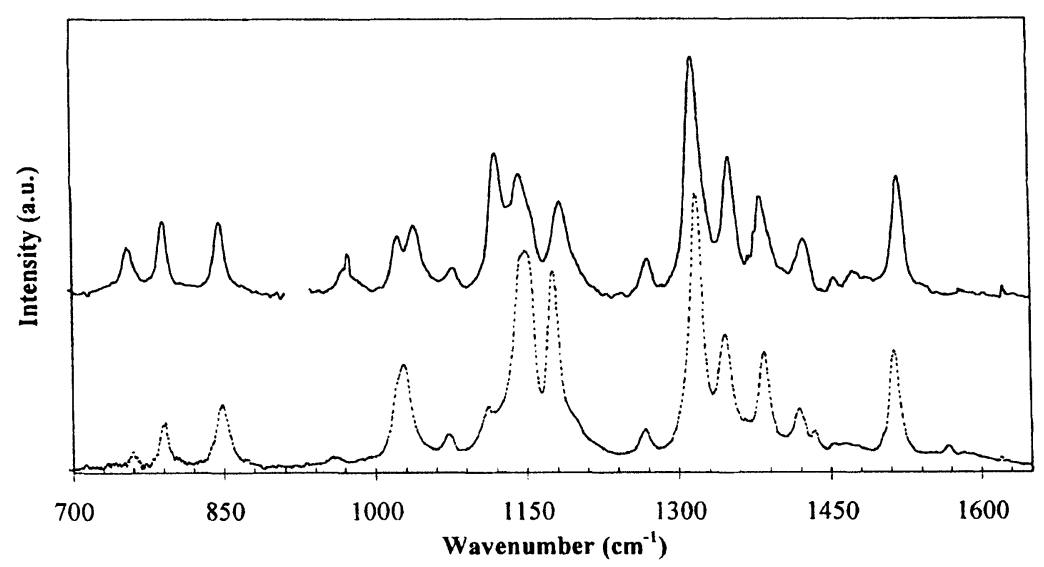

FIGURE $1 \mathrm{TR}^{3}$ spectra of triplet $1 \mathrm{NN}$ in $\mathrm{CCl}_{4}(-)$ and $\mathrm{MeCN}(-)$.

Continuum $8000 \mathrm{Nd}$ :YAG), we obtained the triplet $1 \mathrm{NN}$ species, characterised [7] by a main absorption band at $540 \mathrm{~nm}\left(\mathrm{CCl}_{4}\right)$ or $580 \mathrm{~nm}(\mathrm{MeCN})$. We then observe a quenching of this species and the rise of absorption bands peaking below $380 \mathrm{~nm}\left(\mathrm{CCl}_{4}\right)$ and at $470 \mathrm{~nm}$ followed, at high $t \mathrm{~S}$ concentrations, by a shift towards $465 \mathrm{~nm}$ $(\mathrm{MeCN})$. These absorptions are characteristic of the triplet excited state of $t \mathrm{~S}$ [8], its radical cation [9], and a dimeric species formed by reacion of $t \mathrm{~S}^{+\cdot}$ with ground state $t \mathrm{~S}$ [9] respectively. The absence of $t \mathrm{~S}^{+}$in non-polar solution was confirmed by a $\mathrm{TR}^{3}$ experiment performed with a probe laser beam at $480 \mathrm{~nm}$ (Continuum Sunlite ${ }^{\mathrm{TM}}$ OPO). Similarly, we observed by $\mathrm{TR}^{3}$ spectroscopy the formation of the dimer radical cation of $t \mathrm{~S}$ in $\mathrm{MeCN}$ solution (Fig. 2). The radical cation $t \mathrm{~S}^{+\cdot}$ is characterised in the $1500-1650 \mathrm{~cm}^{-1}$ range by two bands at 1570 and $1607 \mathrm{~cm}^{-1}$ as well as a shoulder at ca $1590 \mathrm{~cm}^{-1}$, whereas the shoulder is absent from the vibrational spectrum of $\left(t \mathrm{~S}_{2}\right)^{+\cdot}$ and also the band at $1607 \mathrm{~cm}^{-1}$ is more intense relative to the band at $1570 \mathrm{~cm}^{-1}$ for the $t \mathrm{~S}^{+}$. These observations are consistent with calculations of the vibrational frequencies of the radical ions of various stilbenes [10] and a recent Raman study of $t \mathrm{~S}$ monomeric and dimeric cations produced by UV irradiation in boric acid matrices [11].

Using the formalism of Marcus - Hush theory to describe the rate of electron transfer [12], and Rehm-Weller theory to estimate the free 


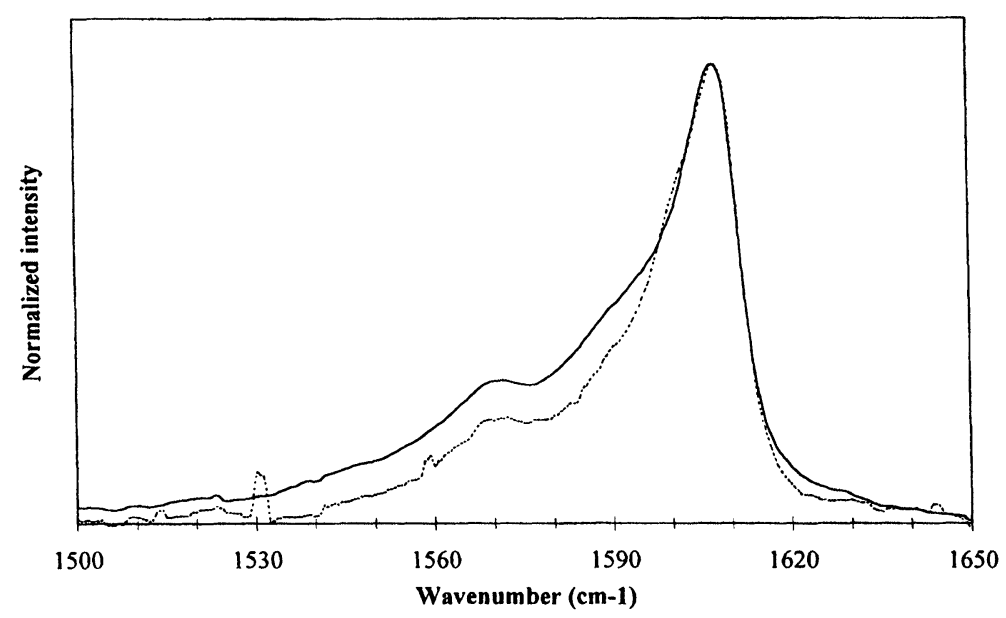

FIGURE 2 Normalised $\mathrm{TR}^{3}$ spectra of $1 \mathrm{NN}(2 \mathrm{mM})+t \mathrm{~S}(3 \mathrm{mM})$ in $\mathrm{MeCN}$ at time delays $50 \mathrm{~ns} \mathrm{(-)} \mathrm{and} 1 \mu \mathrm{s}(-)$. Pump $360 \mathrm{~nm}$, probe $480 \mathrm{~nm}$.

energy $(\Delta G)$ of the electron transfer reaction and the solvent reorganisation energy [13], we can show that the experimental observations can be explained simply [14]. In $\mathrm{CCl}_{4}, \Delta G=0.50 \mathrm{eV}$ and the reaction is thermodynamically unfavourable. In $\mathrm{MeCN}$, $\Delta G=-0.07 \mathrm{eV}$ and $\Delta G^{\#}=0.14 \mathrm{eV}$ and the reaction is possible.

\section{References}

[1] (a) Khalil, O. S., Bach, H. G. and McGlynn, S. P. (1970). J. Mol. Spec., 35, 455; (b) Ohtani, H., Kobayashi, T., Suzuki, K. and Nagakura, S. (1980). Bull. Chem. Soc. Jpn., p. 43; (c) Shioya, Y., Yagi, M. and Higuchi, J. (1989). Chem. Phys. Lett., 154, 25.

[2] Anderson, R. W. Jr., Hochstrasser, R. M., Lutz, H. and Scott, G. W. Chem. Phys. Lett., $28,153$.

[3] Hurley, R. and Testa, A. C. (1968). J. Am. Chem. Soc., 90, 1949.

[4] Rusakowicz, R. and Testa, A. C. (1971). Spectrochim. Acta A, 27A, 787; Mikula, J. J., Anderson, R. W. Jr. Harris, L. E. and Stuebing, E. W. (1972). J. Mol. Spec., 42, 350 .

[5] Bolton, J. R., Mataga, N. and McLendon, G., Eds. (1991). Advances in Chemistry Series 22, American Chemical Society, Washington, DC.

[6] Gaussian 94, Revision C.2, Frisch, M. J., Trucks, G. W., Schlegel, H. B., Gill, P. M. W., Johnson, B. G., Robb, M. A., Cheeseman, J. R., Keith, T., Petersson, G. A., Montgomery, J. A., Raghavachari, K., Al-Laham, M. A., Zakrzewski, V. G., Ortiz, J. V., Foresman, J. B., Cioslowski, J., Stefanov, B. B., Nanayakkara, A., 
Challacombe, M., Peng, C. Y., Ayala, P. Y., Chen, W., Wong, M. W., Andres, J. L., Replogle, E. S., Gomperts, R., Martin, R. L., Fox, D. J., Binkley, J. S., Defrees, D. J., Baker, J., Stewart, J. P., Head-Gordon, M., Gonzalez, C. and Pople, J. A. (1995). Gaussian, Inc., Pittsburgh PA.

[7] Capellos, C. and Porter, G. (1974). J. Chem. Soc. Farad Trans. 2, 70, 1159.

[8] Görner, H. and Schulte-Frohlinde, D. (1981). J. Phys. Chem., 85, 1835.

[9] Akaba, R., Sakuragi, H., Tokumaru, K., Yoshida, Y. and Tagwa, S. (1993). Bull. Chem. Soc. Jpn., 66, 1852.

[10] Schneider, S., Scharnagl, C., Bug, R., Baranovic, G. and Meic, Z. J. Phys. Chem., 96, 9748

[11] Kuriyama, Y. and Oishi, S. (1995). Chem. Lett., p. 149.

[12] Marcus, R. A. (1964). Annu. Rev. Phys. Chem., 15, 155; Hush, N. S. (1968). Electrochim Acta, 13, 1005.

[13] Rehm, D. and Weller, A. (1970). Isr. J. Chem., 8, 259.

[14] Fournier, T., Tavender, S., Parker, A. W., Scholes, G. and Phillips, D. (1997). J. Phys. Chem., 101, 5320. 